\title{
PENGETAHUAN DAN SIKAP REMAJA TERHADAP DISMENOREA DI SMP PNIEL MANADO
}

\author{
${ }^{1}$ Reny A. Tampake \\ ${ }^{2}$ F. Wagey \\ ${ }^{2}$ M.R.Rarung
}

\author{
${ }^{1}$ Kandidat Skripsi Fakultas Kedokteran Universitas Sam Ratulangi Manado \\ ${ }^{2}$ Bagian Obstetri Ginekologi Fakultas Kedokteran Universitas Samratulangi Manado \\ Email: renytampake@yahoo.co.id
}

\begin{abstract}
Dismenorhea or painful menstruation, is one of the most common gynecological disorder. Dysmenorrhoea can be primary, if not accompanied by organic pathology, or secondary when accompanied by pathological disorders. Primary dysmenorrhoea is caused uterine contraction induced by prostaglandin and tends to occur with the onset of ovulatory cycles and usually improve over time, coinciding with the onset of menstrual bleeding. Primary dysmenorrhea peaks in the late teens and early 20s. Dismenorhea affect the lives of young people in various levels of daily activities. This study aims to examine the level of knowledge about the teenage daughter of dysmenorrhoea. This study is an analysis of cross-sectional descriptive study. Results of the study: the age distribution of respondents in the most junior Pniel Manado is 13-15 years (70.7\%), knowledge about adolescent dysmenorrhea is either approximately $77.6 \%$, positive student attitudes about Dismenorhea of $74.1 \%$.
\end{abstract}

Keywords: dismenorrhea, adolescent, knowledge, attitude.

\begin{abstract}
Abstrak: Dismenorhea atau nyeri haid, adalah salah satu gangguan ginekologi yang paling umum. Dismenorea bisa primer, jika tidak disertai dengan patologi organik, atau sekunder jika disertai dengan gangguan patologis. Dismenorea primer disebabkan kontraksi uterus yang disebabkan oleh prostaglandin dan cenderung terjadi dengan timbulnya siklus ovulasi dan biasanya membaik dari waktu ke waktu, bertepatan dengan terjadinya perdarahan menstruasi. Puncak dismenore primer pada remaja akhir dan awal 20-an. Dismenorhea mempengaruhi kehidupan anak muda di berbagai tingkat aktivitas sehari-hari. Penelitian ini bertujuan untuk menguji tingkat pengetahuan tentang dismenorea putri remaja. Penelitian ini merupakan analisis dari penelitian deskriptif cross-sectional. Hasil penelitian: distribusi usia responden yang paling junior Pniel Manado adalah 13-15 tahun (70,7\%), pengetahuan tentang dismenore remaja adalah baik sekitar 77,6\%, sikap siswa positif tentang Dismenorhea dari 74,1\%.
\end{abstract}

Kata kunci: Dismenorea, remaja, pengetahuan, sikap

Dismenorhea atau nyeri haid, adalah salah satu gangguan ginekologi yang paling umum. Dismenorea merupakan penyebab terbesar hilangnya hari-hari kerja dan sekolah di kalangan wanita muda. Dismenorea bisa bersifat primer, bila tidak disertai patologi organik, atau sekunder bila disertai gangguan patologi. Dismenorea primer disebabkan kontrasi uterus yang diinduksi oleh prostaglandin. Dismenorea primer cenderung terjadi dengan timbulnya siklus ovulasi dan biasanya membaik seiring waktu, bertepatan dengan timbulnya per-darahan menstruasi. Gejala-gejala dismenorea primer seringkali dikaitkan dengan gejala-induksi prostaglandin lain seperti mual, muntah, diare, dan pusing. Rasa sakit yang tajam dan kram, dan terletak di garis tengah abdomen bagian bawah., ${ }^{1,2}$ 
Dismenore sekunder berarti nyeri panggul yang disebabkan oleh (sekunder) gangguan atau penyakit. Dismenore sekunder paling sering terjadi pada wanita yang berada di akhir usia belasan atau awal dua puluhan dan kemungkinan akan semakin memburuk. Rasa sakit mungkin mulai jauh sebelum menstruasi dan terus selama dan bahkan setelah menstruasi. Masalah ginekologi yang dapat menyebabkan dismenore sekunder meliputi penyakit radang panggul, leiomyomata, endometriosis, adenomiosis, dan penggunaan alat kontrasepsi. Rasa sakit dismenore sekunder sering terjadi di kedua kuadran abdomen bawah. ${ }^{1,2,3}$

Dismenore mempengaruhi lebih dari $50 \%$ dari wanita menstruasi, dan prevalensi yang dilaporkan telah sangat bervariasi. ${ }^{1,2}$ Sebuah survei dari 113 pasien dalam praktek keluarga menunjukkan prevalensi 29-44\%, tetapi angka sebesar 90 \% pada wanita berusia 18-45 tahun pernah dilaporkan. ${ }^{3}$ Penggunaan kontrasepsi oral (oral) dan obat anti- inflammatory drugs (NSAID), yang keduanya efektif dalam mengatasi gejala dismenore primer, dapat menghalangi penilaian yang akurat prevalensi dis-menorea. ${ }^{4,5}$

Puncak dismenore primer pada remaja akhir dan awal 20-an. Insiden meningkat dengan bertambahnya usia dan dengan meningkatnya paritas. Dalam banyak penelitian, meskipun tidak semua, prevalensi yang dilaporkan dan keparahan dismenore pada wanita parous secara substansial lebih rendah. Sebuah studi epidemiologi tidak menemukan perbedaan yang signifikan dalam prevalensi dan keparahan dismenore antara perempuan nulligravid dan mereka dengan kehamilan diakhiri baik dengan aborsi spontan atau yang diinduksi. ${ }^{1,6}$

Dalam studi epidemiologi dari populasi remaja (rentang usia, 12-17 tahun), dilaporkan bahwa prevalensi dismenorea sebesar 59,7 \%. Dari pasien melaporkan nyeri, $12 \%$ nyeri berat, $37 \%$ moderat, dan $49 \%$ ringan. Dismenore menyebabkan $14 \%$ dari pasien lebih sering bolos sekolah. Meskipun remaja kulit hitam melaporkan tidak ada peningkatan kejadian dismenore, mereka absen dari sekolah lebih sering (23,6 \%) dibandingkan kulit putih (12,3 \%). Prevalensi dysmenorrhea seluruh dunia mirip dengan Amerika Serikat, berkisar dari $15,8 \%$ menjadi $89,5 \%$, dengan tingkat lebih tinggi dilaporkan pada populasi remaja. ${ }^{1,3,6}$

Dismenorhea

mempengaruhi kehidupan remaja dalam berbagai tingkat aktifitas sehari-hari. Perlu dilakukan evaluasi karakteristik menstrual, prevalensi dis-menorea dan pengaruhnya terhadap aktifitas rutin setiap hari serta kualitas hidup para pelajar, serta meningkatkan pengetahuan pelajar untuk mengenali setiap segi dismenorhea dan evaluasi dini bila ada kelainan yang menyertainya.

\section{METODOLOGI PENELITIAN}

Penelitian ini bersifat analisis deskriptif dengan study cross sectional. Populasi adalah seluruh siswi kelas II SMP Pniel Manado. Sampel adalah seluruh siswi kelas II SMP Pniel Manado. Dilakukan sosialisasi tujuan penelitian yang akan dilakukan pada siswi, yang setuju mengisi persetujuan informed consent. Dilakukan wawancara dengan menggunakan kuisioner untuk diisi oleh siswi, dan di kembalikan besok hari kepada peneliti.

\section{HASIL PENELITIAN DAN BAHASAN}

Penelitian sikap dan pengetahuan remaja tentang dismenorrhea, dilakukan di SMP Pniel Manado, dengan responden melibatkan seluruh remaja putri kelas dua SMP Pniel Manado yang berjumlah 58 siswa. Pada awalnya dipilih 60 responden dan dibagikan kuesioner sikap dan pengetahuan tentang dysmenorrhea, namun pada saat pengumpulan kuesioner, hanya 58 siswa yang melengkapi kuesioner dan mengembalikan kepada peneliti. Jadi tersisa 58 responden yang siap untuk diteliti hubungan antara sikap dan pengetahuan remaja putri tentang dysmenorrhea, dengan distribusi sebagai berikut: 
Tampake, Wagey, Rarung; Pengetahuan dan Sikap Remaja...

Distribusi usia responden (Tabel 1) pada SMP Pniel Manado menunjukkan bahwa umur terbanyak adalah 13-15 tahun sebanyak 41 responden atau sebesar 70,7 \%, disusul usia 10-12 tahun sebanyak 12 responden atau sebesar 20,7 \%. Responden ini dipilih pada usia-usia awal menstruasi dengan usia terbanyak adalah yaitu usia antara 10-15 tahun. Dengan hasil ini menunjukkan bahwa walaupun responden belum terlalu lama mengalami menstruasi, dan mungkin dianggap bahwa tingkat pengetahuan mereka tentang dysmenorrhea masih kurang, namun penelitian ini menunjukkan hasil yang sebaliknya.

Tabel 2 menunjukkan bahwa sumber informasi tentang dysmenorrhea yang diperoleh remaja paling banyak dari orang tua sebesar 33,1 \%, yang kedua dari internet sebesar $28 \%$. Peranan orang tua dalam memberikan informasi tentang menstruasi sangat penting untuk mengurangi pengaruh yang menyesatkan dari sumber informasi lain. ${ }^{18,19}$

Tabel 3 menunjukkan bahwa pada penelitian ini, pengetahuan remaja tentang dysmenorrhea adalah baik dengan jumlah responden sebesar 45 orang atau sekitar 77,6 \%. Dari tabel diatas dapat dilihat data mengenai sikap remaja tentang dysmenorrhea menunjukkan bahwa 43 responden $(74,1 \%)$ dengan sikap positif (cenderung mencari bantuan atau melakukan penanganan dysmenorrhea yang mereka alami. Pengetahuan seseorang dipengaruhi oleh berbagai faktor: sosial, ekonomi, kultur, pendidikan dan pengalaman. Dengan pengetahuan yang baik, remaja dapat menangani masalah dysmenorrhea mereka. ${ }^{20}$

Tabel 1. Distribusi responden berdasarkan usia

\begin{tabular}{|c|c|c|c|}
\hline Age & Frequency & Percent & Valid Percent \\
\hline $10-12$ & 12 & 20,7 & 20,7 \\
\hline Valid 13-15 & 41 & 70.7 & 70.7 \\
\hline$>16$ & 5 & 8,6 & 8,6 \\
\hline Total & 58 & 100,0 & 100,0 \\
\hline
\end{tabular}

Tabel 2. Distribusi responden berdasarkan sumber informasi

\begin{tabular}{lccc}
\hline $\begin{array}{l}\text { Sumber } \\
\text { informasi }\end{array}$ & Frequency & Percent & $\begin{array}{c}\text { Valid } \\
\text { percent }\end{array}$ \\
\hline Orang tua & 40 & 33,1 & 33,1 \\
Internet & 35 & 28,9 & 28,9 \\
Media & 23 & 19,0 & 19,0 \\
Teman & 23 & 19,0 & 19,0 \\
$\quad$ Total & 121 & 100,0 & 100,0 \\
\hline
\end{tabular}

Tabel 3. Pengeatahuan siswa tentang dismenorrhea

\begin{tabular}{lcccc}
\hline Frequency & Percent & $\begin{array}{c}\text { Valid } \\
\text { Percent }\end{array}$ & $\begin{array}{c}\text { Cumulative } \\
\text { Percent }\end{array}$ \\
\hline Baik & 45 & 77,6 & 77,6 & 77,6 \\
Cukup & 13 & 22,4 & 22,4 & 100,0 \\
Total & 58 & 100,0 & 100,0 & \\
\hline
\end{tabular}

Tabel 4. Sikap siswa tentang dismenorrhea

\begin{tabular}{lcccc}
\hline & Frequency & Percent & $\begin{array}{c}\text { Valid } \\
\text { Percent }\end{array}$ & $\begin{array}{c}\text { Cumulative } \\
\text { Percent }\end{array}$ \\
\hline Negatif & 15 & 25,9 & 25,9 & 25,9 \\
Positif & 43 & 74,1 & 74,1 & 100,0 \\
Total & 58 & 100,0 & 100,0 & \\
\hline
\end{tabular}

\section{SIMPULAN}

Penelitian sikap dan pengetahuan remaja tentang dysmenorrhea yang dilakukan pada SMP Pniel Manado, telah dilakukan dan disimpulkan dengan jumlah responden 58 orang dengan kesimpulan:

1. Ada hubungan pengaruh antara tingkat pengetahuan tentang dysmenorrhea dengan sikap remaja untuk penanganan dysmenorrhea.

2. Informasi tentang dysmenorrhea paling banyak ditemukan dari internet.

3. Tingkat pengetahuan remaja putri tentang dysmenorrhea di SMP Pniel adalah baik.

4. Sikap siswa SMP Pniel terhadap dysmenorrhea adalah baik, artinya dengan pengetahuan mereka yang baik, mereka memiliki sikap yang baik (tepat) untuk penanganan sendiri atau untuk mencari bantuan masalah dysmenorrhea yang mereka alami. 


\section{DAFTAR PUSTAKA}

1. Karim Anton, C., \& Michael R, R.Dysmenorrhea. Medscape refference.2013

2. Noorbakhsh, M., Alijani, E., \& Kohandel, M. The effect of physical activity on primary dysmenorrhea. World Applied Sciences Journal, 2012;17(10), 1246-1252.

3. Pallavi, L., Rita, C., \& Khalid, K. Dysmenorrhea. Clinical Evidence Handbook, BMJ Publishing Group, 2012;15(85), 386-387.

4. Gumanga S.K., Aryee K. Prevalence and severity of dysmenorrhea among some adolescent girls in secondary school in Accra, Ghana. Postgraduate Medical Journal of Ghana. 2012;1(1):1-8

5. Shrotriya, C., Ray, A., \& Ray, S. G. Menstrual characteristics and prevalence and effect of dysmenorrhea on quality of life of medical students. International Journal of Collaborative Research on Internal Medicine \& Public,2013;4(4), 275285.

6. Tinatin, G., Besarion, T., \& David, G. Primary dysmenorrhea: prevalence in adolescent population of Tbilisi, Georgia and risk factors. J Turkish-German Gynecol Assoc, 2012;13:162-8.

7. Gagua T., Tkeshelashvili, Gagua D. Primary dysmenorrhea: prevalence in adolescentpopulation of Tbilisi, Georgia and risk factors. J Turkish-German Gynecol Assoc 2012;13:162-8

8. Baghianimoghadam M.H., Loo A.M., Falahzadeh H., Alavijeh M.M. A Survey about the Prevalence of Dysmenorrhea inFemale Students of Shahid Sadoughi University of MedicalSciences and Their Knowledge, and Practice toward it. Journal of Community Health Research. 2012;1(2):93-98

9. Levebvre G., Pinsonneault O., et all. Primary dismenorrhea consensus guideline. SOGG Clinical Practice Guideline. 2005:165:1117-1127

10. Rao, V., Kiran R., Vijayasree M. Oksidative stress and antioxidan status in primary dysmenorrhea. Journal of clinical and diagnostic research. 2011:5(3):509-511
11. DHMH/FHA/CMCH. Dismenorrhea. Maryland State Family Planning Program Clinical Guidelines. 2011:1-3

12. Dawood MY. Primary dismenorrhea. Advance in Pathogenesis and Management. Clinical Expert Series. Continuing Medical Education. 2006:108(2):428-440

13. Proctor ML, Smith CA, Farquhar CM and Stones RW. Transcutaneouselectrical nerve stimulation and acupuncture for primary dysmenorrhea(Cochrane Review). In: The Cochrane Library. Issue 2, 2004.

14. Proctor ML, Hing W, Johnson TC, Murphy PA. Spinal manipulation forprimary and secondary dysmenorrhea (Cochrane Review). In: The CochraneLibrary. Volume 2, 2004.

15. Notoatmojo S. Ilmu kesehatan masyarakat. Rhineka, Jakarta. 2003;2.

16. Berek JS. Novak's Gynecology. Lippincott Williams \& Wilkins, Philadelphia, PA, 2007;2.

17. Kabirian M, Abedian Z, Mazlom SR, Mahram B. Self-management in primary dysmenorrhea: toward evidence-based education. Life science journal. 2011;8:148.

18. Chiou MH, Wang H, Yang $Y$ (2007). Effect of Systematic Menstrual Health Education on Dysmenorrheic Female Adolescents' Knowledge, Attitudes, and Self-Care Behavior. The Kaohsiung Journal of Medical Sciences. 2007;23(4):183-90.

19. Jalili Z, Safi Zadeh H, Shams Poor N. Prevalence of primary dysmenorrhea in college students in Sirjan, Kerman. Payesh, 2009;4(1): 61-7.

20. Kamjo A. Prevalence and related factors of primary dysmenorrhea in college students in Bandar Abbas. Journal of Hormozgan University of Medical Science. 2008; 3: 69. 